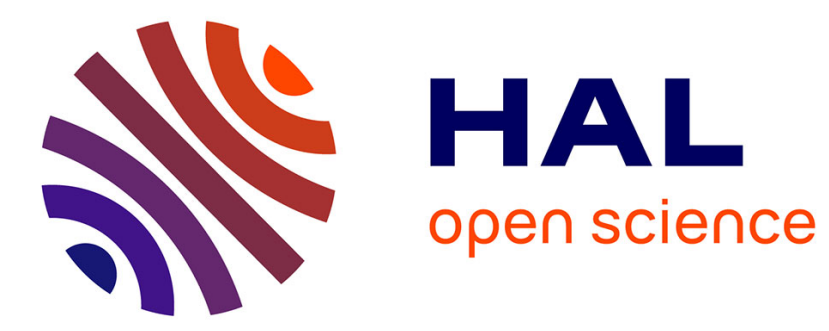

\title{
Urban alien plants in temperate oceanic regions of Europe originate from warmer native ranges
}

Charly Géron, Jonas Lembrechts, Jan Borgelt, Jonathan Roger Michel Henri

Lenoir, Rafiq Hamdi, Grégory Mahy, Ivan Nijs, Arnaud Monty

\section{- To cite this version:}

Charly Géron, Jonas Lembrechts, Jan Borgelt, Jonathan Roger Michel Henri Lenoir, Rafiq Hamdi, et al. Urban alien plants in temperate oceanic regions of Europe originate from warmer native ranges. Biological Invasions, 2021, 23 (6), pp.1765-1779. 10.1007/s10530-021-02469-9 . hal-03362904

\section{HAL Id: hal-03362904 https://hal.science/hal-03362904}

Submitted on 2 Oct 2021

HAL is a multi-disciplinary open access archive for the deposit and dissemination of scientific research documents, whether they are published or not. The documents may come from teaching and research institutions in France or abroad, or from public or private research centers.
L'archive ouverte pluridisciplinaire HAL, est destinée au dépôt et à la diffusion de documents scientifiques de niveau recherche, publiés ou non, émanant des établissements d'enseignement et de recherche français ou étrangers, des laboratoires publics ou privés. 


\section{Alien plants on a city trip: Urban invaders originate from warmer native ranges}

2 Géron, Charly ${ }^{a, b^{*}}$, Lembrechts, Jonas Johan ${ }^{b}$, Borgelt, Jan ${ }^{c}$, Lenoir, Jonathan ${ }^{d}$, Hamdi, Rafiq ${ }^{e, f}$, Mahy,

3 Grégory $^{\mathrm{a}}$, Nijs, Ivan ${ }^{\mathrm{b}}$ and Monty, Arnaud ${ }^{\mathrm{a}}$

4 aBiodiversity and Landscape, TERRA research centre, Gembloux Agro-Bio Tech, University of Liège,

5 Gembloux, 5030, Belgium

6 bPlants and Ecosystems, University of Antwerp, Wilrijk, 2610, Belgium

7 'Department of Energy and Process Engineering, Norwegian University of Science and Technology (NTNU),

8 Trondheim 7491, Norway

9 dUR «Écologie et dynamique des systèmes anthropisés » (EDYSAN, UMR 7058 CNRS), Université de

10 Picardie Jules Verne, Amiens, 80037, France

11 eRoyal Meteorological Institute, Brussels, 1180, Belgium

12 fDepartment of Physics and astronomy, Ghent University, Ghent, 9000, Belgium

$13{ }^{*}$ Corresponding author: Charly Géron, cgeron@uliege.be, 0032 (0)81 622546

14

15 E-mail addresses:

16 Géron, Charly: cgeron@uliege.be

17 Lembrechts, Jonas Johan: jonas.lembrechts@uantwerpen.be

18 Borgelt, Jan: jan.borgelt@ntnu.no

19 Lenoir, Jonathan: jonathan.lenoir@u-picardie.fr

20 Hamdi, Rafiq: rafiq.hamdi@meteo.be; rafiq.hamdi@ugent.be

21 Mahy, Grégory: g.mahy@uliege.be

22 Nijs, Ivan: ivan.nijs@uantwerpen.be

23 Monty, Arnaud: arnaud.monty@uliege.be

Short title: Urban alien plants come from warmer climates

Acknowledgments: This work was supported by the Fonds de la Recherche Scientifique (FNRS). 


\section{Abstract}

35 Aim: To test the long-expected connection between the native climatic conditions of alien plant species 36 and their preference for urban versus rural conditions, a hypothesis driven by the presence of warmer

37 and drier microclimates in cities due to the urban heat island effect.

38 Location: Western Europe.

39 Time period: $1950-2018$.

40 Major taxa studied: Plants.

41 Methods: We evaluated the relationship between climate in the native range and occurrence urbanity of

4224 emerging alien plant species in western Europe, based on land imperviousness data obtained from

43 land.copernicus.eu.

44 Results: Alien species growing in more urban environments originated from warmer or drier native 45 ranges than the invaded area.

46 Main conclusions: These results have important implications for alien species management as climate

47 warming in oceanic Europe will likely lift climatic barriers that currently constrain numerous alien plant 48 species to cities, boosting the role of cities as points of entry for invasive plants.

49

50 Keywords: alien plant species, biological invasions, urbanization, native climate, global changes 
53 The second half of the twentieth century has been characterized by a steep rise in international trade,

54 travel, and transport, resulting in the biotic homogenization of the world through increased alien species 55 introductions (Olden \& Rooney 2006; Pyšek et al. 2010; van Kleunen et al. 2018). Data from Europe shows 56 that most introductions happened after 1990, during the so-called "globalization era" (Hulme 2009). The 57 success and speed of alien species invasion depend on the propagule pressure of alien species and the 58 lifting of certain barriers, such as lower abiotic or biotic constraints in the introduced range (Dullinger et 59 al. 2017). Only a small portion of introduced alien species passes all of these barriers (Walther et al. 2009) 60 to become invasive, and significantly impacts native biota (Dullinger et al. 2017). Alien plant invasions 61 occur in all habitats, extending from rural to urban ones; however, the susceptibility to invasion (i.e., 62 invasibility) of these habitats varies. Some land use categories, especially the most anthropogenic ones 63 (e.g., urban areas), display higher alien plant invasions and often concentrate newly arrived alien plant 64 species, due to high propagule pressure, concentration of transport infrastructure, and recurring 65 anthropogenic disturbance (Botham et al. 2009; Catford et al. 2011; Godefroid \& Ricotta 2018). In 66 particular, climatic conditions are recognized as the first filter that either holds back alien plant species or 67 allows successful establishment and spread in novel regions (Richardson et al. 2000). In recent decades, 68 an increasing number of thermophilous (e.g., warm-loving) and drought-resistant alien plant species has 69 been introduced to temperate regions, with some surviving up to $1000 \mathrm{~km}$ further north than their natural range limits, at colder latitudes and altitudes, where they are not naturally present (McKinney 2006; Walther et al. 2009). The establishment, survival, and spread of such plant species from warmer origins might depend on "heat islands," such as urban areas; yet, this hypothesis has not been formally assessed (Walther et al. 2009). Therefore, urban environments represent useful systems to study climatic constraints on the invasion success of alien plant species (Brans et al. 2017; van Kleunen et al. 2018). Urban environments provide unique growing conditions for plants. However, the intensity to which environmental conditions are modified by human activities sharply decreases from city centers towards rural peripheries (Alberti et al. 2003; Ortega \& Pearson 2005; Schmidt et al. 2014). One common and wellknown aspect of urban environments is their modified microclimate. Indeed, city areas are warmer than the rural surroundings, which is a phenomenon called the urban heat island (UHI) effect (Oke et al. 2017; Bader et al. 2018). Three main factors contribute to the establishment of urban heat islands: 3-D urban 81 geometry, thermal characteristics of impervious surfaces, and anthropogenic heat release. Local background climate also strongly contributes to the magnitude of the urban heat island (Zhao et al. 2014; 
characterize urbanization. Areas with $10 \%$ built up surfaces are considered to be urban in western Europe (Kaiser et al. 2016; Brans et al. 2017). Plant urbanity (i.e., the proportion of built up surface in the plant's vicinity) is used to characterize its growing environment in relation to urbanization (Hill et al. 2002). The high percentage of impervious surfaces associated with intense anthropogenic activity modify soil characteristics and disrupt the water cycle, resulting in highly fluctuating amounts of surface runoff water (Hamdi et al. 2011). Consequently, urban habitats induce warmer and drier microclimates, broadening regional climatic variation, whereas rural habitats present naturally occurring climatic conditions of a given region. Native niche conditions of alien plants that are newly introduced to foreign environments strongly influence their establishment, and determine their population growth and capacity to spread (Alexander \& Edwards 2010). Native niche optimum is often used to characterize climatic suitability for alien plant species (van Kleunen et al. 2015). Urban-to-rural gradients show variability in their microclimatic conditions, and might filter alien plant species based on their native niche optimum. For example, the preference of native plants for urban habitats is often related to the level of thermophily; in other words, plants mostly found in cities would be pre-adapted to the warmer and drier urban conditions (McKinney 2006; Schmidt et al. 2014; Szymura et al. 2018).

Existing studies have demonstrated that a high number of urbanophile plant species are thermophilous, with the high diversity and proportion of alien plant species in cities being positively coupled to city size and percentage of built-up surface (Schmidt et al. 2014; Čeplová et al. 2017); however, a comprehensive assessment of the supposed link between climatic conditions in the native range and the level of urbanity in the invaded range of alien plant species remains unproven, to the best of our knowledge. This is a crucial step towards identifying the characteristics of more urban alien species for conserving native species more effectively, as their high number and diversity has already transformed cities into invasion hotspots. This phenomenon will likely be amplified in the future by global changes if urban invasion is, indeed, strongly driven by the microclimate. Since the surrounding landscape will become warmer in parallel, these urban alien plants might subsequently spill over more abundantly to the rural surroundings, using cities as stepping stone for further spread.

This study evaluated 24 emerging alien plant species originating from outside western Europe, using oceanic Europe (area of western Europe with a temperate climate, with warm summers but no dry season) as the study zone. The study aimed to: (a) disentangle the relationships between the climatic conditions

113 in the native range (i.e., niche optimum) and the level of urbanity in the invaded range, while taking the

114 first date of observation in the wild into account, and (b) test whether more urban alien plant species 115 originate from native ranges with a warmer climate than that of the invaded range. 
117 Study area, species selection, and native ranges

118 To delineate our study area, we used the Köppen-Geiger climate classification and focused on the temperate oceanic climate of Europe (Fig. 1): Cfb (i.e., temperate climatic conditions with warm summers and no dry season) (Beck et al. 2018). This geographic entity was considered to represent the invaded range in this study, and is referred to as "oceanic Europe" in this study (Fig. 1). This delineation was chosen

122 to keep the background macroclimatic conditions as homogeneous as possible, and to better contrast with 123 the urban heat island (UHI) effect of the main cities occurring in the study area. We then selected a list of 124 alien plant species growing in terrestrial environments, which stages of invasion are still considered as 125 incipient with distributions that remain restricted in oceanic Europe, but which are also having moderate 126 to high impacts on biodiversity. This selection was based on the Harmonia database ("Harmonia database" 127 2019) and European Union (EU) Regulation no. 1143/2014. Species with unclear native ranges (e.g., 128 hybrids) were removed. This led to an initial total of 33 species eligible for inclusion (Fig. 2).

129 Alien species distribution data

130 Modelled native ranges

131 Native countries and native regions for each of the 33 species were retrieved from Plants of the World 132 Online (POWO 2020) and occurrences were acquired from the Global Biodiversity Information Facility 133 (GBIF 2020) using the R packages rgbif and taxize (Chamberlain et al. 2019, 2020). Native regions were 134 reported following the World Geographical Scheme for Recording Plant Distributions (WGSRPD) and range 135 from continental to regional scale (Brummitt et al. 2001). In order to minimize variability in number of 136 occurrence points across countries, a maximum of 300 occurrence points was retrieved from GBIF (GBIF 137 Secretariat 2019) for each species per native country. By default, this included only the most recent 138 occurrence points. Then, only the points falling inside reported native WGSRPD regions were kept. 139 Duplicates were removed, as well as outliers that were detected based on Mahalanobis distance (MD) and 140 defined as any points having an MD four times larger than the 0.95 percentile of the entirety (Mahalanobis 141 1936). MD was calculated for each occurrence based on its location and bioclimatic conditions. Since 142 outliers already influence the calculations of MD, we applied this approach again after removing the first 143 set of outliers. Since species distributions hardly follow any administrative boundaries, we define the 144 modelling extent for each studied alien plant species as all ecoregions (Olson et al. 2001) containing at 145 least one of its remaining occurrence points. Furthermore, to acknowledge the fact that defining native 146 countries and WGSRPD regions as well as data availability within ecoregions may be suspect to errors and 147 biases, we included all neighboring ecoregions as well. WorldClim bioclimatic predictors and land cover 
148 types were used to predict the possible native range of each species at 30 arcmin resolution across the

149 defined modelling extent using maximum entropy modelling (Maxent) (Phillips et al. 2004, 2006, 2017).

150 WorldClim bioclimatic predictors ( $n=19$, see https://www.worldclim.com/bioclim for full list) (Fick \&

151 Hijmans 2017) were downloaded in 10 arcmin resolution and aggregated to modelling resolution (30

152 arcmin, approximately $56 \mathrm{~km}$ at the equator) by averaging. Land cover classes ( $\mathrm{n}=22$, including different

153 types and mosaics of vegetation, see http://maps.elie.ucl.ac.be/Ccl/viewer/download/CCl-

154 LC_Maps_Legend.pdf for full list) were calculated based on the European Space Agency's land cover

155 product (original scale $300 \mathrm{~m} \times 300$ m, ESA 2017). Each class was transformed into a binary raster depicting

156 presence $(=1)$ or absence $(=0)$ of the land cover type, and then aggregated to modelling resolution by

157 averaging, resulting in one raster for each land cover class. Handling of spatial data was conducted using

158 the R packages raster, rgdal, maptools, rgeos and sp (Bivand et al. 2013, 2019; Bivand \& Lewin-Koh 2019;

159 Bivand \& Rundel 2019; Hijmans 2019). Maxent is a probability density estimation approach suitedfor

160 predicting species distributions based on presence-only data (Elith et al. 2006). In Maxent, environmental

161 variables and transformations thereof are used to predict species distributions. For our spatial predictions,

162 we kept the Maxent default settings for selecting appropriate variables, transformations (out of linear,

163 quadratic, product, hinge and threshold) and regularization values used to reduce overfitting (Elith et al.

164 2011; Merow et al. 2013). In addition, Maxent requires background information to contrast the

165 environmental background against presence locations, and ultimately, fit response curves (Elith et al.

166 2011). We collected background information from each cell across the modelling extent to avoid fitting

167 the model with randomly generated points. Model fitting, prediction and range generation were executed

168 with the R package dismo (Hijmans et al. 2017). The Maxent prediction was transformed into presence

169 cells using the cut-off threshold that maximized model sensitivity for each species. This step results in a

170 patchy landscape consisting of suitable and unsuitable habitat patches. We temporarily increased the

171 extent of each patch by $10 \%$ using buffering, to remove patches that would not contain any occurrence

172 points, hence, removing patches that are unlikely being colonized by the species. This gave us a native

173 range area estimation for each of the studied alien plant species, and the 19 WorldClim bioclimatic

174 predictors (Fick \& Hijmans, 2017) were further sampled with a $5 \mathrm{~km} \times 5 \mathrm{~km}$ grid over each of them. These

175 bioclimatic predictors data were used to depict climatic conditions in the modelled native ranges of species

176 (Fig. 2). Finally, for each of the 24 species, we defined the main Köppen-Geiger climate class (Beck et al.

177 2018) for its modelled native range as the class in which most of native range area $5 \mathrm{~km} X 5 \mathrm{~km}$ fishnet

178 points fell.

179 
181 The occurrence of the selected alien plant species, for the invaded ranges, was downloaded from the 182 Global Biodiversity Information Facility (GBIF, see Appendix S1 Table S1.2 in Supporting Information, GBIF.org, 2019), were acquired for 1950-2018, and were handled in ArcMap 10.5.1 (2017). This time period was set because it encompassed $90 \%$ of the observations available on GBIF.org across all species. We only included species with at least 50 observations in the invaded range, which led to the removal of 9 out of 33 species, and a final list of 24 species (Fig. 2, see Appendix S1 Table S1.2 in Supporting Information). The invaded distribution data of species were processed to correct for variation in the resolution of data in GBIF.org, and to solve high local spatial autocorrelation for example bias towards areas with high occurrence densities. To do so, fishnets of $5 \mathrm{~km} \mathrm{X} 5 \mathrm{~km}$ were placed over oceanic Europe. In each cell, and for each species, if several occurrence records were present, only a randomly chosen one was kept. This resulted in a total of 20000 processed occurrence records for oceanic Europe (See Appendix S2 in Supporting Information for details on species occurrence and maps in modelled native ranges and oceanic Europe). The density of impervious areas, representing the percentage of built-up land surface in 2015 (land.copernicus.eu, 2018) was used to characterize the level of urbanization throughout the invaded range of each study species (Fig. 2). To do so, the imperviousness layer was aggregated, using the mean, at a spatial resolution of $5 \mathrm{~km} \times 5 \mathrm{~km}$ (original scale: $20 \mathrm{~m} \mathrm{X} 20 \mathrm{~m}$ ), to match the resolution of the occurrence datasets. The proportion of impervious area was extracted for each occurrence cell in the invaded range, and the mean value was calculated for each species. This parameter was subsequently referred to as "mean urbanity" (value between 0 and 1) (Fig. 2). Moran's index was calculated for each species in ArcMap 10.5.1 (2017), checking for spatial autocorrelation in the processed occurrences of each of the alien plant species in oceanic Europe.

\section{Statistical analyses}

203 A principal component analysis (PCA) was conducted on the bioclimatic conditions within the modelled native ranges ( $R$ package factoextra, Kassambara and Mundt, 2017) to simplify the large set (19) of explanatory variables to a 3-dimensional climatic niche space. The three first PCA axes were retained, with the three bioclimatic predictors that contributed the most to each of these three PCA axes. We extracted

207 the values (i.e., coordinates) along the three first PCA axes for the sampled $5 \mathrm{~km} \mathrm{X} 5 \mathrm{~km}$ points over the 208 modelled native ranges of each studied alien species (Fig. 1). The first three PCA axes explained 39\%, 22\%, and $14 \%$ variance, respectively, of the WorldClim bioclimatic data (Table 1).

The minimum temperature of the coldest month (Bio 6, positively correlated), the mean temperature of the coldest quarter (i.e., the coldest four months of the year, Bio 11, positive), and the annual mean 
212 temperature range (Bio 1, positive) contributed the most to PCA axis 1 (Table 1). This first PCA axis, thus,

213 represented the severity of the native winter climate, and the extent of temperature variations throughout

214 the year. High values along this PCA axis indicate a native range climate with milder winter temperatures

215 and little annual variation in temperature. Thus, we called this axis native "winter temperature" 216 conditions.

217 The annual precipitation (Bio 12, positive), precipitation of the driest quarter (Bio 17, positive), and 218 precipitation of the driest month (Bio 14, positive) contributed the most to PCA axis 2 (Table 1). The second

219 PCA axis thus represented the precipitation amount of the native range climate, with high values indicating 220 more precipitations. The second PCA axis thus reflected native "precipitation" conditions.

221 The mean temperature of the warmest quarter (Bio 10, positive), maximum temperature of the warmest 222 month (Bio 5, positive), and mean temperature of the wettest quarter (Bio 8, positive) contributed the 223 most to the third PCA axis (Table 1). High values along this PCA axis meant warmer high temperature values 224 in the native range climate. The third PCA axis thus represented native "summer temperature" conditions. 225 The mean position along these three PCA axes was calculated for each focal species separately, to depict 226 niche optimum. This parameter was referred to as "barycenter".

227 The date of first observation of the studied species in oceanic Europe was derived from Zieritz et al. 2017 228 and the "Harmonia database" 2019, and compiled the first observation data in Belgium, France, Great 229 Britain, and the Netherlands, which are the countries having the biggest area in oceanic Europe.

230 The analysis of the relationships for mean urbanity (response variable) with respect to the species 231 barycenter and the date of first observation (explanatory variables) was performed using betaregressions 232 (R package betareg, Cribari-Neto \& Zeileis 2010), as we hypothesized that native climatic conditions 233 explained the distribution of alien plant species in urban versus rural areas in oceanic Europe. The response 234 variable, mean urbanity, was continuous, and was derived from proportions and restricted to the unit 235 interval $(0,1)$, but no values were exactly equal to 0 or 1 , thus justifying the use of betaregressions (Douma 236 \& Weedon 2019). The full model included all one-way interactions of the explanatory variables. We used 237 the dredge function (package MuMIn, Barton, 2019) to select the models to be averaged. In other words, 238 the best model had the lowest Akaike Information Criterion (AIC) and highest Phi coefficient (model 239 precision), and selected models had a delta AIC lower than 2 relative to the best model. Using this 240 procedure, two candidate models were retained. We then performed model averaging on these selected 241 models (R package MuMIn, Barton, 2019).

242 To characterize the origin of the studied alien plant species in term of native bioclimatic values, baseline 243 values for each of the 19 WorldClim bioclimatic predictors were calculated as their mean value over the 
species respective native ranges. To compare those values with climatic conditions occurring in the invaded range, baseline values for each of the 19 WorldClim bioclimatic predictors were calculated as their mean value over the oceanic Europe study zone. To define the species as more urban or more rural, a cutoff value of mean urbanity of the studied species was obtained by calculating the mean of the mean urbanity of the 24 studied species $(=8.6 \%)$. This mean urbanity cut-off value was used to distinguish species displaying a mean urbanity above this threshold as more urban, and species displaying a mean

250 urbanity below this threshold as more rural, in oceanic Europe. Confusion matrixes were produced for all 251 of the bioclimatic predictors, and only the best is shown here. Following their position along the reference 252 values, species considered as true positive (TP), true negative (TN), false positive (FP), and false negative 253 (FN) were determined. The precision of species placement was calculated as $\frac{T P}{(T P+F P)}$. Finally, a generalised 254 linear model was used to test the relationship of the mean urbanity of the studied species (response variable) with their main native climate, which was described as the main Köppen-Geiger climate class in which they occur in their native range (explanatory variable, treated as factor) (package car, John et al., 2019). A binomial family was used, with the response variable being treated as a vector accounting for the urbanity and non-urbanity percentages (i.e. c(\%urbanity, \%non-urbanity)) following the method of Crawley, 2013. All statistical analyses were performed in R, version 1.1.463 (RStudio Team 2016).

Results

\section{Native climatic conditions and invaded urbanity of alien plant species}

263 The 24 studied alien plant species showed high variability in native climatic conditions, with native ranges encompassing a total of 26 out of the 30 Köppen-Geiger climate classes, yet with $87 \%$ of occurrences in seven of the 30 climate classes. The urbanity of all occurrence records and species together in oceanic Europe ranged from 0 to 93\%; mean species-level urbanity varied between 4 and 17\%. 22 of the 24 studied alien plant species displayed a high spatial autocorrelation.

Alien plant species from warmer and drier origins are more likely to develop in higher urbanity areas in oceanic Europe

270 The averaged betaregression model explaining the mean urbanity in oceanic Europe of a given alien plant 271 species included the position of the barycenter of the bioclimatic niche of the species along PCA axes 2

272 and 3, and the date of first observation in the wild (Table 2).

273 Native climate "precipitation" (PCA axis 2) had a negative effect and "summer temperature" (PCA axis 3)

274 had a positive effect on species mean urbanity in oceanic Europe, both displaying the strongest support 
overall (Table 2; present in the 2 selected models). Thus, in oceanic Europe, alien plant species from warmer (PCA axis 3) and/or drier (PCA axis 2) native ranges were, on average, found in more urban 277 environments (Fig. 3a and b).

278 The date of first observation in the wild had a weak positive but not significant effect on species mean urbanity, and was only present in one of the selected models (Fig. 3c). Alien plant species present in the wild for a more recent period of time were found in more urban environments.

281 The main native Köppen-Geiger climate class had a non-significant effect on species mean urbanity $(p>$ $2820.05, \mathrm{Df}=3, \mathrm{LR}$ Chisq = 5.79). However, visualization of the main Köppen-Geiger climate classes (Fig. 3a) 283 showed that more urban alien species primarily originated from subtropical or continental climates in the native range. In comparison, more rural alien species primarily originated from contrasted and/or cooler climates in the native range (e.g., alpine or continental) (Fig. 3, 4).

286 The confusion matrix of mean annual temperature had the strongest correlation with the urbanity of alien species, with the highest estimation precision (0.58). This result highlights the importance of mean annual temperature as a driver of the urbanity of alien species in oceanic Europe. Seven out of the 12 more urban aliens originated from native ranges with warmer mean annual temperatures compared to the mean annual temperature in oceanic Europe (TP, Fig. 4). In addition, ten out of the 12 more rural alien species originated from native ranges with cooler mean temperature compared to oceanic Europe (TN, Fig. 4).

\section{Discussion}

293 The current study showed that the variation in the urbanity of alien plant species was largely explained by the climatic conditions in their modelled native ranges. Native niche optimum, accounted for the PCA axis barycenters in our study, had a preponderant importance. A predominant proportion of more urban and more rural alien species originated from warmer and cooler native ranges, respectively, compared to the studied area, in terms of mean annual temperature. Alien plants that grew in more urban environments primarily originated from two main climate types: subtropical and continental climates. In comparison, alien plants that grew in more rural environments appeared to mainly originate from alpine, continental, and Mediterranean climates. Yet, variation in the native climate was more important for these rural alien species compared to more urban alien species.

302 We acknowledge that the date of first observation in the wild had a slight but not significant effect, and that we could not robustly prove that alien plant species spreading more recently were usually found in more urban environments. Even though the propagule pressure of the studied alien species is not the same everywhere in oceanic Europe; the introduction of plant species tends to happen at higher rates in densely inhabited areas. Alien species also tend to escape from cultivated areas, such as gardens, present 
in urban and rural areas (Botham et al. 2009; Dullinger et al. 2017). However, we noticed that the occurrence of the studied alien species exhibited broad variety of urbanity values, showing that they were present in all types of environments, from densely built metropolitan areas (London, Paris, etc.) in highly urbanized regions (Flanders, Netherlands) to extensive rural zones (central France, Wales, etc.). Western Europe has the highest road and rail density of any continent, and is considered to be the world's most urbanized region (Hulme 2009; Terama et al. 2019). Consequently, the displacement of propagules is far easier in this region compared to less human-modified parts of the world. Thus, we argue that the preference of some alien species in our study for more urban or more rural environments, could be linked to climatic filtering of urban climate. Indeed, our study indicates that alien plants of various origins do not establish randomly along the imperviousness gradient; rather, alien plant species from warmer and/or drier native ranges tend to establish in more urban environments, visible by the predominant effect of the native climate barycenters.

Oceanic Europe has a temperate mild and humid climate; however, urban environments have elevated summer temperatures due to the UHI-effect, and a modified water cycle due to impervious surfaces. These phenomena result in warmer and drier local conditions compared to rural surroundings (Ortega \& Pearson 2005; Walther et al. 2009; Kaiser et al. 2016; Szymura et al. 2018). Therefore, we hypothesize that it is more likely that alien species from warmer and drier native ranges than those in our study area develop in more urban environments, induced by the presence of warmer and drier microclimates in oceanic European cities.

More urban aliens from subtropical climates likely take advantage of the longer growing season and reduced winter freezing events associated with the UHI (Walther et al. 2009; Schmidt et al. 2014). The first developmental stages of several alien plant species from subtropical climates are particularly sensitive to temperature. For instance, the germination of Baccharis halimifolia and Lonicera japonica are optimal at around $20-25^{\circ} \mathrm{C}$ (Schierenbeck 2004; Fried et al. 2016), representing a relatively high temperature range for oceanic Europe. Moreover, seedlings of such species also tend to be highly frost sensitive, as illustrated by the high mortality of Ailanthus altissima seedlings after freezing events (von der Lippe et al. 2005). The phenology of these species often involves late flowering and fruiting, which represent crucial stages sensitive to the earliness, duration, and intensity of freezing events (e.g., Baccharis halimifolia, (Fried et al. 2016), Cyperus eragrostis (lefländer \& Lauerer 2007), and Potentilla indica (Dakskobler \& Vreš 2009)). In addition, urban environments display more drained and disturbed substrates (Schmidt et al. 2014) that might represent conditions with favorable humidity for more urban aliens from drier native ranges that are adapted to either limited and/or seasonal precipitation regimes in an oceanic humid climatic region. 
339 Some of the alien species in our study prefer disturbed and/or drained soil conditions (e.g., Reynoutria 340 sachalinensis (Sukopp \& Starfinger 1995)), and germinate better under contrasted temperatures (e.g. 341 Elaeagnus augustifolia, (Guilbault et al. 2012)). The urban microclimate also promotes the survival of the 342 seedlings of some of these species (e.g., Acer negundo, (von der Lippe et al. 2005)).

343 Conversely, alien plant species associated with lower urbanity in oceanic Europe tend to originate from 344 cooler ranges, which might perform less well in warmer and drier urban environments, limiting their 345 development in cities. Warmer temperatures inhibit the development abilities of some of these species, 346 especially for young individuals (e.g., Lupinus polyphillus (Elliott et al. 2011) and Lysichiton americanus (Schrader \& Klingenstein 2006)), whereas drier substrates negatively impact the development of species, such as Prunus laurocerasus (Berger et al. 2007) and Spiraea alba (Stanton and Mickelbart, 2014)). The separation of more urban aliens from the whole alien species pool indicates that urban conditions could act as a strong filter for warmth and drought-adapted plant species. This phenomenon is of great conservation concern, because many ornamental species introduced to temperate regions originate from dry and warm areas (van Kleunen et al. 2018). Moreover, urban environments might enhance alien plant invasions in the future, due to higher environmental disequilibrium caused by enhanced urbanization, trade, and climate change (van Kleunen et al. 2018). Because urban areas are highly connected with rural surroundings, they actively export propagules (Hulme 2009; Catford et al. 2011). Under climate change, surrounding rural areas will become suitable for drought and warm adapted species, in addition to urban environments (Kendal et al. 2012). Cities could act as veritable migration outpost for these climate limited alien plant species, facilitating their escape to newly suitable rural areas (Hulme 2009; Dullinger et al. 2017; Pyšek et al. 2017). This study demonstrated that global databases (such as GIBF.org, WorldClim, Copernicus Imperviousness Density), if cautiously used, are relevant for analyses at a continental scale. The strong relationship between urbanity in the invaded range and climatic conditions in the modelled native range, at a continental scale, suggests that even stronger microclimatic effects might be at play at local scales, as suggested by previous studies (Botham et al. 2009; Walther et al. 2009; Lembrechts et al. 2018). Even if we acknowledge variability within species and limited number of studied species, the strong pattern found in the current study confirmed that this global relationship with climatic conditions of origin is consistent, and highlighted that multi-species studies are essential for comprehending invasion processes and urban invasion ecology (Catford et al. 2011). In an era of biotic homogenization (Pyšek et al. 2010; Terama et al. 2019), urban environments could represent hotspots for invasion by new alien plant species. Therefore, emphasis should be placed on 
371 invasion processes and monitoring invasion in urban environments to advance our understanding on what 372 drives the early stages of invasion, when it might still be controlled. Furthermore, this phenomenon might 373 be compounded by the fact that warmer and drier climates might become more common across the whole 374 urban-to-rural gradient under climate change (Hamdi et al. 2015; Brans et al. 2017). Therefore, it is 375 important to raise the awareness of public institutions and private property owners, especially since 376 massive urban plantations, such as public and/or private gardens, which could help cities adapt to climate 377 change, might otherwise represent potential sites for the "seeding" of future plant invasions (Essl 2007; 378 Gaertner et al. 2017).

379

380 
Alberti, M., Marzluff, J.M., Shulenberger, E., Bradley, G., Ryan, C. \& Zumbrunnen, C. (2003). Integrating Humans into Ecology: Opportunities and Challenges for Studying Urban Ecosystems. Bioscience, 53, 1169-1179.

Alexander, J.M. \& Edwards, P.J. (2010). Limits to the niche and range margins of alien species. Oikos, 119, 1377-1386.

Bader, D.A., Blake, R., Grimm, A., Hamdi, R., Kim, Y., Horton, R., et al. (2018). Urban Climate Science. In: Climate Change and Cities. Cambridge University Press, pp. 27-60.

Barton, K. (2009). MuMIn: multi-model inference.

Beck, H.E., Zimmermann, N.E., Mcvicar, T.R., Vergopolan, N., Berg, A. \& Wood, E.F. (2018). Data Descriptor: Present and future Köppen-Geiger climate classification maps at 1-km. Sci. Data, 5.

Berger, S., Söhlke, G., Walther, G.R. \& Pott, R. (2007). Bioclimatic limits and range shifts of cold-hardy evergreen broad-leaved species at their northern distributional limit in Europe. Phytocoenologia, $37,523-539$.

Bivand, R., Keitt, T. \& Rowlingson, B. (2019). rgdal: Bindings for the "Geospatial" Data Abstraction Library. https://CRAN.R-project.org/.

Bivand, R. \& Lewin-Koh, N. (2019). maptools: Tools for Handling Spatial Objects. R package version 0.9-5. https://CRAN.R-project.org/.

Bivand, R., Pebesma, E. \& Gomez-Rubio, V. (2013). Applied spatial data analysis with R, Second edition. Springer, NY.

Bivand, R. \& Rundel, C. (2019). rgeos: Interface to Geometry Engine - Open Source ("GEOS"). R package version 0.5-1. https://CRAN.R-project.org/.

Botham, M.S., Rothery, P., Hulme, P.E., Hill, M.O., Preston, C.D. \& Roy, D.B. (2009). Do urban areas act as foci for the spread of alien plant species? An assessment of temporal trends in the UK. Divers. Distrib., 15, 338-345.

Brans, K.I., Govaert, L., Engelen, J.M.T., Gianuca, A.T., Souffreau, C. \& De Meester, L. (2017). Ecoevolutionary dynamics in urbanized landscapes: Evolution, species sorting and the change in zooplankton body size along urbanization gradients. Philos. Trans. R. Soc. B Biol. Sci., 372, 1-11.

Brummitt, R.K., Pando, F., Hollis, S. \& Brummitt, N.A. (2001). World Geographical Scheme for Recording Plant Distributions. Int. Work. Gr. Taxon. Databases Plant Species, 153.

Catford, J.A., Vesk, P.A., White, M.D. \& Wintle, B.A. (2011). Hotspots of plant invasion predicted by propagule pressure and ecosystem characteristics. Divers. Distrib., 17, 1099-1110.

Čeplová, N., Kalusová, V. \& Lososová, Z. (2017). Effects of settlement size, urban heat island and habitat type on urban plant biodiversity. Landsc. Urban Plan., 159, 15-22.

Chamberlain, S., Barve, V., Mcglinn, D., Oldoni, D., Desmet, P., Geffert, L., et al. (2020). rgbif: Interface to the Global Biodiversity Information Facility API. R package version 1.3.0.

Chamberlain, S., Szocs, E., Foster, Z., Arendsee, Z., Boettinger, C., Ram, K., et al. (2019). taxize: Taxonomic 
information from around the web. R package version 0.9.9. https://github.com/ropensci/taxize.

434 Crawley, M.J. (2013). The R Book. R B. Chichester, West Sussex, United Kingdom.

435 Cribari-Neto, F. \& Zeileis, A. (2010). Beta Regression in R. J. Stat. Softw., 34, 1-24.

436 Dakskobler, I. \& Vreš, B. (2009). Cyperus eragrostis Lam. - A new adventitious species in the Flora of 437 Slovenia. Hacquetia, 8, 79-90.

Douma, J.C. \& Weedon, J.T. (2019). Analysing continuous proportions in ecology and evolution: A practical introduction to beta and Dirichlet regression. Methods Ecol. Evol., 10, 1412-1430.

Dullinger, I., Wessely, J., Bossdorf, O., Dawson, W., Essl, F., Gattringer, A., et al. (2017). Climate change will increase the naturalization risk from garden plants in Europe. Glob. Ecol. Biogeogr., 26, 43-53.

Elith, J., H. Graham, C., P. Anderson, R., Dudík, M., Ferrier, S., Guisan, A., et al. (2006). Novel methods improve prediction of species' distributions from occurrence data. Ecography (Cop.)., 29, 129-151.

Elith, J., Phillips, S.J., Hastie, T., Dudík, M., Chee, Y.E. \& Yates, C.J. (2011). A statistical explanation of

Elliott, C.W., Fischer, D.G. \& LeRoy, C.J. (2011). Germination of Three Native Lupinus Species in Response to Temperature . Northwest Sci., 85, 403-410.

ESA. (2017). Land Cover CCI Product User Guide Version 2. Tech. Rep.

Essl, F. (2007). From ornamental to detrimental? The incipient invasion of Central Europe by Paulownia tomentosa. Preslia, 79, 377-389.

Fick, S.E. \& Hijmans, R.J. (2017). Worldclim 2: New 1-km spatial resolution climate surfaces for global land areas. Int. J. Climatol.

Fox, J. \& Weisberg, S. (2019). An R Companion to Applied Regression.

Fried, G., Caño, L., Brunel, S., Beteta, E., Charpentier, A., Herrera, M., et al. (2016). Botany Letters Monographs on Invasive Plants in Europe: Baccharis halimifolia L. Bot. Lett., 163, 127-153.

Gaertner, M., U Wilson, J.R., Cadotte, M.W., Scott Maclvor, J., Zenni, R.D., Richardson, D.M., et al. (2017). Non-native species in urban environments: patterns, processes, impacts and challenges. Biol. Invasions, 19, 3461-3469.

GBIF. (2020). The Global Biodiversity Information Facility: What is GBIF?

GBIF Secretariat. (2019). GBIF Backbone Taxonomy. Checklist dataset. Available at: https://doi.org/10.15468/39omei . Last accessed .

Godefroid, S. \& Ricotta, C. (2018). Alien plant species do have a clear preference for different land uses within urban environments. Urban Ecosyst, 21, 1189-1198.

Guilbault, K.R., Brown, C.S., Friedman, J.M. \& Shafroth, P.B. (2012). The influence of chilling requirement on the southern distribution limit of exotic Russian olive (Elaeagnus angustifolia) in western North America. Biol. Invasions, 14, 1711-1724.

Hamdi, R., Giot, O., De Troch, R., Deckmyn, A. \& Termonia, P. (2015). Future climate of Brussels and Paris for the 2050s under the A1B scenario. Urban Clim., 12, 160-182. 
Hamdi, R., Termonia, P. \& Baguis, P. (2011). Effects of urbanization and climate change on surface runoff of the Brussels Capital Region : a case study using an urban soil - vegetation - atmosphere-transfer model. Int. J. Climatol., 31, 1959-1974.

Harmonia database. (2019). Belgian Forum on Invasive Species. Available at: https://ias.biodiversity.be/definitions\#legal. Last accessed 20 September 2019.

Hijmans, R.J. (2019). raster: Geographic Data Analysis and Modeling. R package version 3.0-7.

Hijmans, R.J., Phillips, S., Leathwick, J. \& Elith, J. (2017). dismo: Species Distribution Modeling. R package version 1.1-4.

Hill, M.O., Roy, D.B. \& Thompson, K. (2002). Hemeroby, urbanity and ruderality : bioindicators of disturbance and human impact. J. Appl. Ecol., 39, 708-720.

Hulme, P.E. (2009). Trade, transport and trouble: managing invasive species pathways in an era of globalization. J. Appl. Ecol., 46, 10-18.

lefländer, A. \& Lauerer, M. (2007). Spontanvorkommen von Duchesnea indica : Ein Neophyt breitet sich in den letzten Jahren verstärkt aus. Berichte der Bayer. Bot. Gesellschaft, 77, 187-200.

Kaiser, A., Merckx, T. \& Van Dyck, H. (2016). The Urban Heat Island and its spatial scale dependent impact on survival and development in butterflies of different thermal sensitivity. Ecol. Evol., 6, 4129-4140.

Karger, D.N., Conrad, O., Böhner, J., Kawohl, T., Kreft, H., Soria-Auza, R.W., et al. (2017). Climatologies at high resolution for the earth's land surface areas. Sci. Data.

Kassambara, A. \& Mundt, F. (2017). Package "factoextra" for R: Extract and Visualize the Results of Multivariate Data Analyses. $R$ Packag. version.

Kendal, D., Williams, N.S.G. \& Williams, K.J.H. (2012). A cultivated environment: Exploring the global distribution of plants in gardens, parks and streetscapes. Urban Ecosyst., 15, 637-652.

van Kleunen, M., Dawson, W. \& Maurel, N. (2015). Characteristics of successful alien plants. Mol. Ecol., 24, 1954-1968.

van Kleunen, M., Essl, F., Pergl, J., Brundu, G., Carboni, M., Dullinger, S., et al. (2018). The changing role of ornamental horticulture in alien plant invasions. Biol. Rev., 93, 1421-1437.

Lembrechts, J.J., Rossi, E., Milbau, A. \& Nijs, I. (2018). Habitat properties and plant traits interact as drivers of non-native plant species' seed production at the local scale. Ecol. Evol., 8, 4209-4223.

von der Lippe, M., Säumel, I. \& Kowarik, I. (2005). Cities as drivers for biological invasions - The role of urban climate and traffic. Die Erde, 136, 123-143.

Mahalanobis, P.C. (1936). On the generalized distance in statistics. Proc. Natl. Inst. Sci. India, 2, 49-55.

McKinney, M.L. (2006). Urbanization as a major cause of biotic homogenization. Biol. Conserv., 127, 247260.

Merow, C., Smith, M.J. \& Silander, J.A. (2013). A practical guide to MaxEnt for modeling species' distributions: what it does, and why inputs and settings matter. Ecography (Cop.)., 36, 1058-1069.

Oke, T.R., Mills, G., Christen, A. \& Voogt, J.A. (2017). Urban Climates. Cambridge University Press, 
Cambridge.

Olden, J.D. \& Rooney, T.P. (2006). On defining and quantifying biotic homogenization. Glob. Ecol. Biogeogr., 15, 113-120.

Olson, D., Dinerstein, E., Wikramanayake, E., Burgess, N., Powell, G., Underwood, E., et al. (2001). Terrestrial Ecoregions of the World: A New Map of Life on Earth. Bioscience, 51, 933-938.

Ortega, Y.K. \& Pearson, D.E. (2005). Weak vs. strong invaders of natural plant communities: assessing invasibility and impact. Ecol. Appl., 15, 651-661.

Phillips, S.J., Anderson, R.P., Dudík, M., Schapire, R.E. \& Blair, M.E. (2017). Opening the black box: an open-source release of Maxent. Ecography (Cop.)., 40, 887-893.

Phillips, S.J., Anderson, R.P. \& Schapire, R.E. (2006). Maximum entropy modeling of species geographic distributions. Ecol. Modell., 190, 231-259.

Phillips, S.J., Dudík, M. \& Schapire, R.E. (2004). A maximum entropy approach to species distribution modeling. Proceedings, Twenty-First Int. Conf. Mach. Learn. ICML 2004, 655-662.

POWO. (2020). Plants of the World Online. Facilitated by the Royal Botanic Gardens, Kew. Published on the Internet.

Pyšek, P., Jarošík, V., Hulme, P.E., Kühn, I., Wild, J., Arianoutsou, M., et al. (2010). Disentangling the role of environmental and human pressures on biological invasions across Europe. Proc. Natl. Acad. Sci. U. S. A., 107, 12157-12162.

Pyšek, P., Pergl, J. \& Essl, F. (2017). Naturalized alien flora of the world: species diversity, taxonomic and phylogenetic patterns, geographic distribution and global hotspots of plant invasion. Preslia, 89, 203-274.

Richardson, D.M., Pyšek, P., Rejmánek, M., Barbour, M.G., Panetta, F.D. \& West, C.J. (2000). Naturalization and invasion of alien plants: concepts and definitions. Divers. Distrib., 6, 93-107.

RStudio Team. (2016). RStudio: Integrated Development Environment for R.

Schierenbeck, K.A. (2004). Japanese Honeysuckle (Lonicera japonica) as an Invasive Species; History, Ecology, and Context. CRC. Crit. Rev. Plant Sci., 23, 391-400.

Schmidt, K.J., Poppendieck, H.H. \& Jensen, K. (2014). Effects of urban structure on plant species richness in a large European city. Urban Ecosyst., 17, 427-444.

Schrader, G. \& Klingenstein, F. (2006). Pest Risk Analysis for Lysichiton americanus Hultén \& ST. John (Araceae).

Schroeder, F.-G. (1970). Exotic Amelanchier species naturalised in Europe and their occurrence in Great Britain. Watsonia, 8, 155-162.

Stanton, K.M. \& Mickelbart, M. V. (2014). Maintenance of water uptake and reduced water loss contribute to water stress tolerance of Spiraea alba Du Roi and Spiraea tomentosa L. Hortic. Res., 1, $1-7$.

Sukopp, H. \& Starfinger, U. (1995). Reynoutria sachalinensis in Europe and in the Far East: A comparison of the species ecology in its native and adventive distribution range. In: Plant invasion - general aspects and special problems. pp. 151-159. 
544 Szymura, T.H., Szymura, M., Zając, M. \& Zając, A. (2018). Effect of anthropogenic factors, landscape 545 structure, land relief, soil and climate on risk of alien plant invasion at regional scale. Sci. Total $546 \quad$ Environ., 626, 1373-1381.

547 Terama, E., Clarke, E., Rounsevell, M.D.A., Fronzek, S. \& Carter, T.R. (2019). Modelling population 548 structure in the context of urban land use change in Europe. Reg Env. Chang., 19, 667-677.

549 Walther, G.R., Roques, A., Hulme, P.E., Sykes, M.T., Pyšek, P., Kühn, I., et al. (2009). Alien species in a $550 \quad$ warmer world: risks and opportunities. Trends Ecol. Evol., 24, 686-693.

551 Ward, K., Lauf, S., Kleinschmit, B. \& Endlicher, W. (2016). Heat waves and urban heat islands in Europe: A 552 review of relevant drivers. Sci. Total Environ., 569-570, 527-539.

553 Zhao, L., Lee, X., Smith, R.B. \& Oleson, K. (2014). Strong contributions of local background climate to $554 \quad$ urban heat islands. Nature, 511, 216-219.

555 Zieritz, A., Gallardo, B., Baker, S.J., Britton, R.J., van Valkenburg, Johan L C H Verreycken, H. \& Aldridge, 556 D.C. (2017). Changes in pathways and vectors of biological invasions in Northwest Europe. Biol $557 \quad$ Invasions, 19, 269-282.

558

559 Data accessibility statement: no new data were used.

560

561

562

563

564 
Tables

567 Table 1: Results of the Principal Component Analysis (PCA) for the 19 WorldClim bioclimatic predictors.

\begin{tabular}{c|c|c|c|c}
$\begin{array}{c}\text { PCA } \\
\text { Dimension }\end{array}$ & $\begin{array}{c}\text { Predictor } \\
\text { number }\end{array}$ & Name short & $\begin{array}{c}\text { Contribution } \\
(\%)\end{array}$ & Correlation \\
\hline \multirow{3}{*}{ Dimension 1 } & Bio 6 & Minimum temperature coldest & 12.3 & 0.96 \\
& Bio 7 & Mean temperature Coldest Quarter & 12.2 & 0.95 \\
& Bio 11 & Annual mean temperature & 10.9 & 0.90 \\
\hline \multirow{3}{*}{ Dimension 2 } & Bio 3 & Annual precipitation & 15.4 & 0.81 \\
& Bio 14 & Precipitation driest quarter & 14.9 & 0.80 \\
& Bio 17 & Precipitation driest month & 13.9 & 0.77 \\
\hline \multirow{3}{*}{ Dimension 3 } & Bio 10 & Mean temperature warmest & 1.95 & 0.72 \\
& Bio 5 & Maximum temperature warmest & 1.73 & 0.68 \\
& Bio 8 & Mean temperature wettest & 1.58 & 0.64 \\
\hline
\end{tabular}


569 Table 2: Estimates and corresponding p-values of the total mean urbanity variance explained by the averaged model. Significant effects are 570 displayed in bold. $\mathrm{N}$ = number of species. Variables contained in each model of the selection used in the model averaging are represented by the

571 following numbers: 1 = PCA axis 2 barycenter; 2 = PCA axis 3 barycenter; 3 = Date of first observation. The variables, pseudo R², Log-likelihood, and 572 corresponding AICC are detailed for each model. The pseudo $\mathrm{R}^{2}$ of the best model of all (Model 1 ) indicates that $43 \%$ of the variance in the data 573 was explained by the model.

574

\begin{tabular}{ccc}
\hline & mean & precision \\
\hline (Intercept) & $\mathbf{- 2 . 2 3 1 * * *}(0.06)$ & \\
PCA axis 2 barycenter & $-\mathbf{0 . 1 7 3 * *}(0.055)$ & \\
PCA axis 3 barycenter & $\mathbf{0 . 1 1 9 ^ { * * } ( 0 . 0 4 5 )}$ & \\
Date of first observation & $0.05(0.068)$ & \\
& & $\mathbf{1 7 1 . 0 9 3 ^ { * * }}$ \\
(phi) & & $(51.13)$ \\
\hline Significance: ${ }^{* * *}=\mathrm{p}<0.001 ;^{* *}=\mathrm{p}<0.01 ;^{*}=\mathrm{p}<0.05$ & \\
\hline
\end{tabular}

\begin{tabular}{ccccc}
\hline & $\mathrm{N}=24$ & & \\
\hline & & & \multicolumn{2}{c}{ Log- } \\
Averaged models: & Variables & Pseudo R & likelihood & AlCc \\
\hline Model 1 & $1,2,3$ & 0.43 & 59.66 on 5 Df & -106.0 \\
Model 2 & 1,2 & 0.36 & 57.94 on 4 Df & -105.8
\end{tabular}


577 Figure 1: Map of the Cfb climate zones in Europe (i.e., temperate climate with warm summers but no dry 578 season, Beck et al. 2018), displayed in green and hereafter called "oceanic Europe".

579

580

581

582

583

584

585

586

587

588

589

590

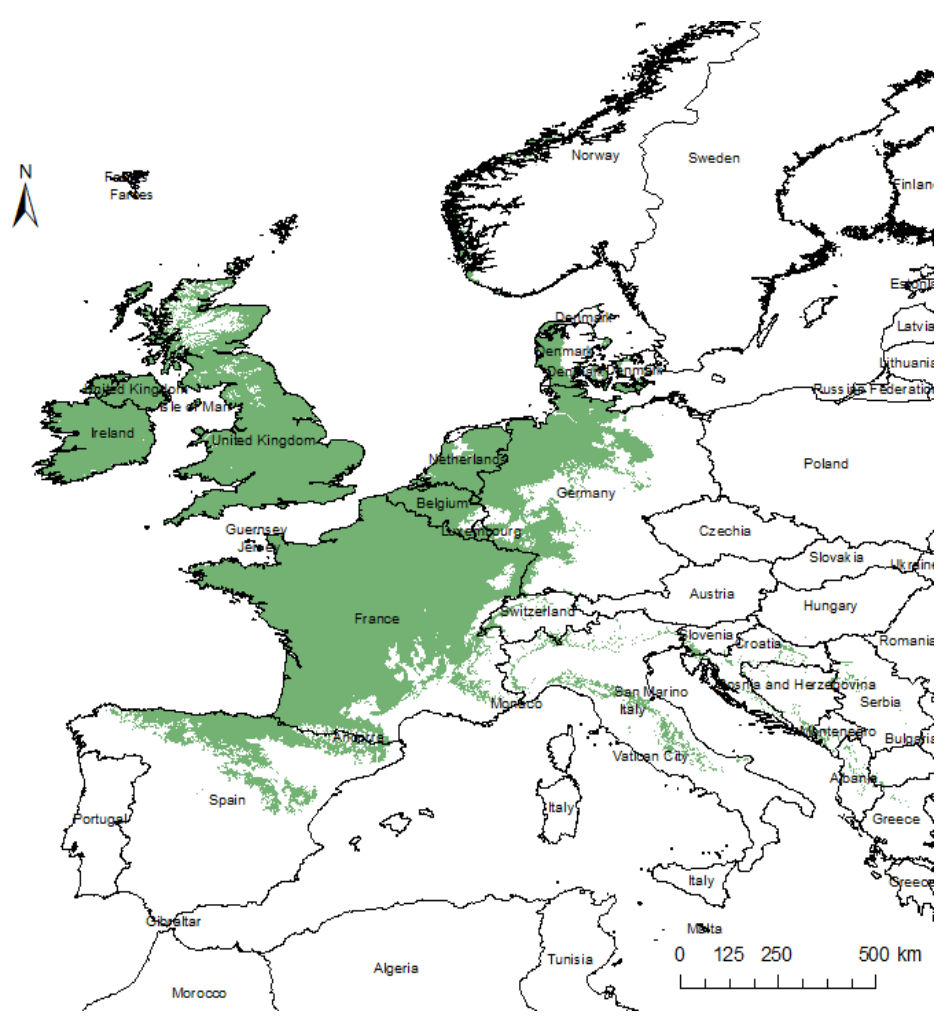

591

592

593

594

595

596

597

598

599

600 
601 Figure 2: Organizational chart of data acquisition, treatment, and analyses.

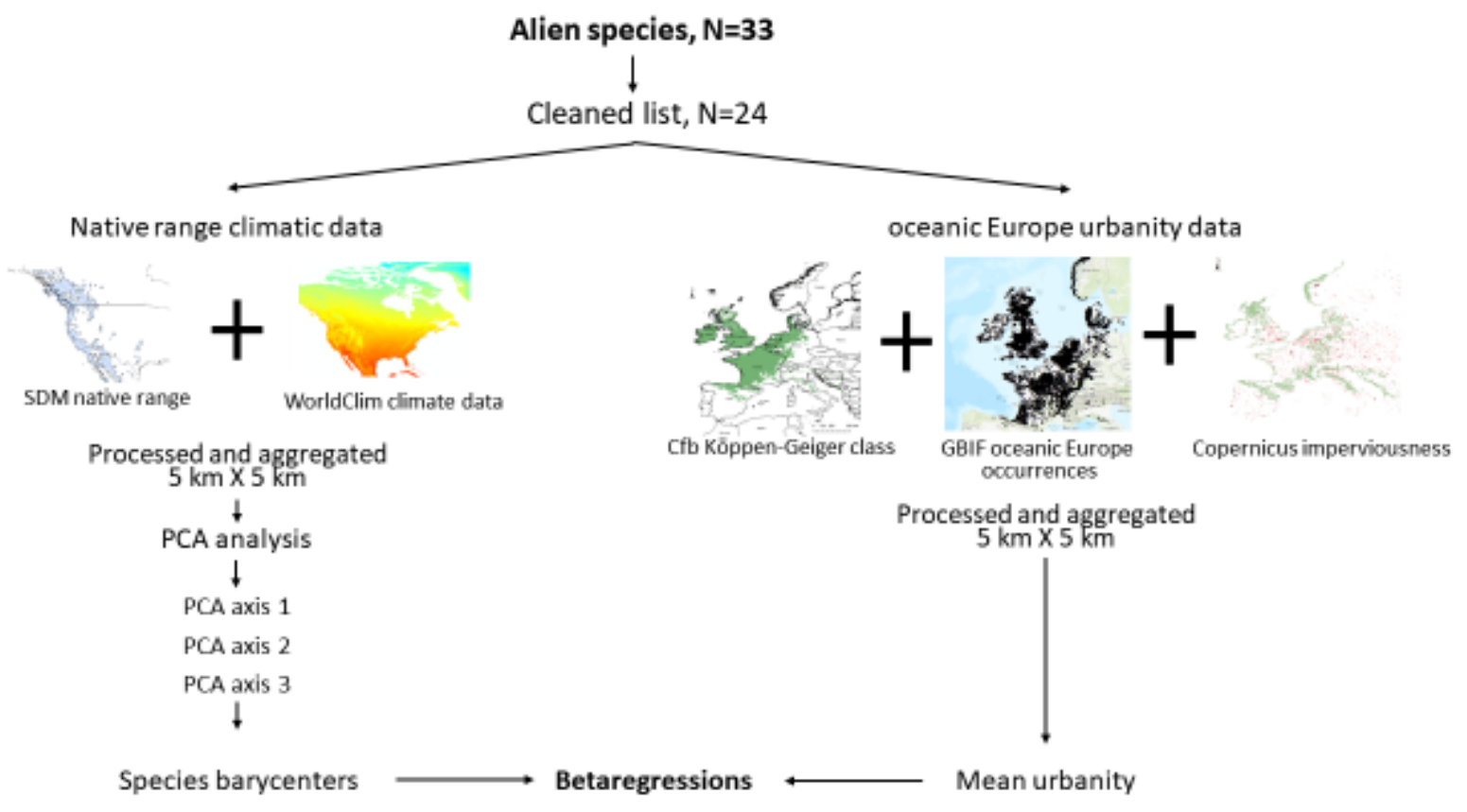

602

603

604 
605 Figure 3: Mean urbanity (in \%) of the studied alien plant species as a function of their native range barycenter 606 calculated from the three first dimensions of the PCA conducted with WolrdClim bioclimatic predictors. Mean 607 urbanity of alien plant species: a) as a function of the barycenter of species for PCA axis 2, mainly associated 608 with the bioclimatic predictors of "precipitation"; b) as a function of the barycenter of species for PCA axis 3, 609 mainly associated with the bioclimatic predictors of "summer temperature", and c) as a function of the scaled 610 date of first observation in the wild. Each point corresponds to a species, colored as a function of the main 611 Köppen-Geiger climate class in which it was observed the most in its modelled native range. Lines correspond

612 to the averaged model output (predicted mean urbanity, \%) in oceanic Europe. Full lines correspond to 613 significant effect in the full averaged model, and dashed line corresponds to a non-significant effect in the full 614 averaged model.

615
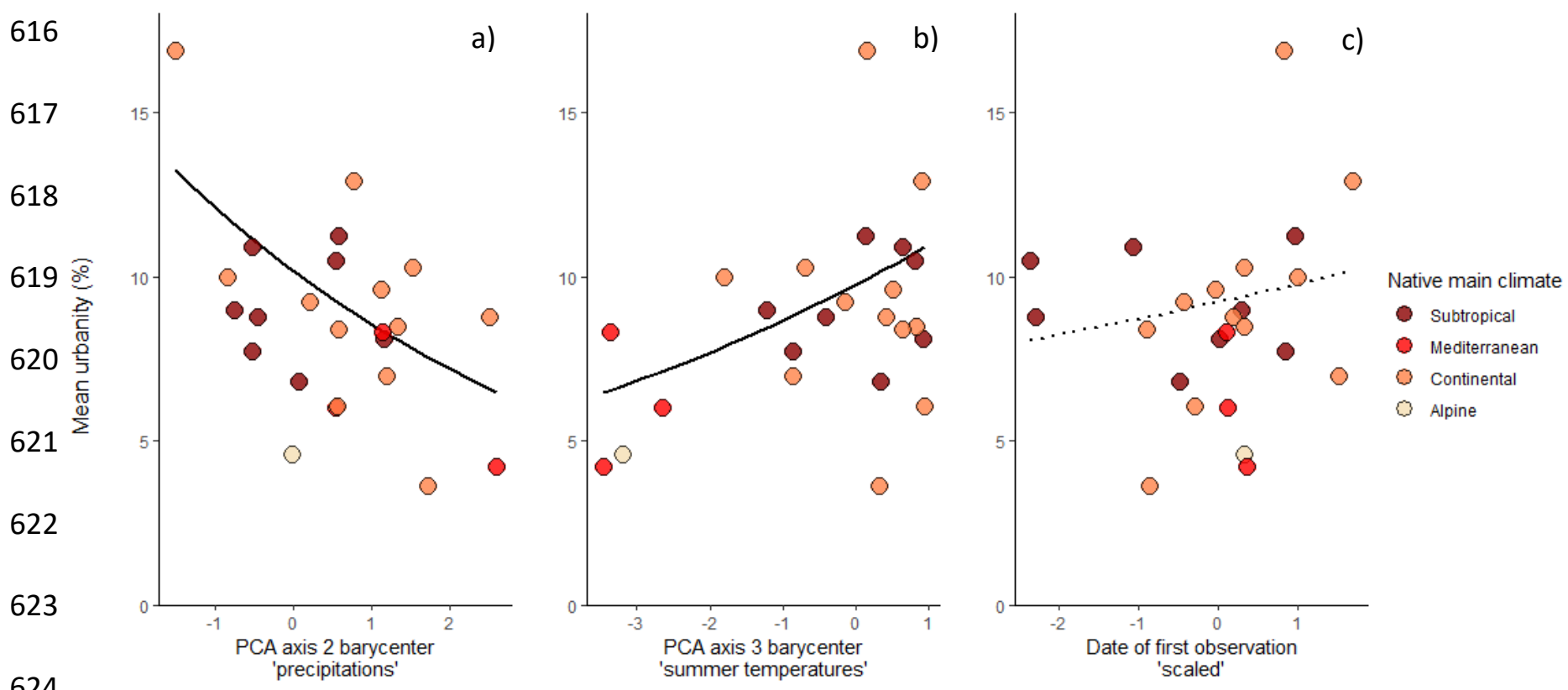

625

626

627

628

629 
631 Figure 4: Mean urbanity of alien plant species in oceanic Europe as a function of their native range mean

632 annual temperature $\left({ }^{\circ} \mathrm{C}\right)$. Each point corresponds to a different species. The full vertical line represents the

633 mean annual temperature $\left({ }^{\circ} \mathrm{C}\right)$, considered as the reference in oceanic Europe: $9.9^{\circ} \mathrm{C}$. The dashed horizontal

634 line corresponds with the mean urbanity value for the set of studied species: 8.6; species with lower mean

635 urbanity than this value were considered to be more rural aliens in oceanic Europe (i.e. 12 out of the 24

636 studied species); with higher urbanity than this value were considered as more urban aliens in oceanic Europe

637 (i.e. 12 out of the 24 studied alien species). Species are colored following their native main Köppen-Geiger

638 climate class. Species represented with squares correspond to either true negative or true positive in the

639 confusion matrix, and species represented with circles are either false negatives or false positives.

640

641

642

FP

0

644

645

646

6

648

649

650

651

652

653

654

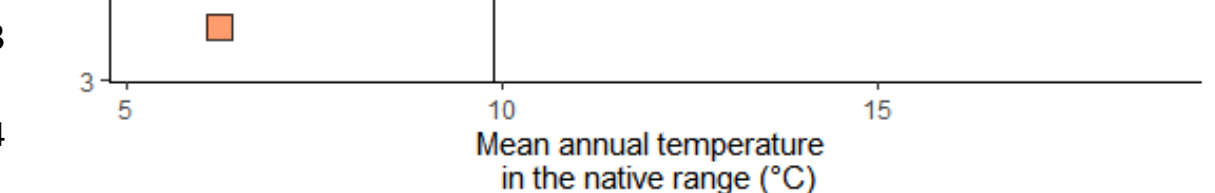

in the native range $\left({ }^{\circ} \mathrm{C}\right)$

655 